\title{
Formação de professores, educação infantil e diversidade étnico-racial: saberes e fazeres nesse processo
}

\author{
LUCIMAR ROSA DIAS \\ Universidade Federal de Mato Grosso do Sul
}

Há muito, homens e mulheres dedicados a combater o racismo na sociedade brasileira apontam a educação escolar e, por consequência, a ação dos professores como importantes para o fomento de valores nos quais a discriminação racial, o racismo e o preconceito não estejam presentes. São ricas, diferenciadas e múltiplas as ações desenvolvidas pelo movimento negro para alcançar tal intuito, por isso há uma produção a ser conhecida e compreendida nesse universo.

Essas organizações articulam-se em diversos momentos da história brasileira, com ações mais contundentes em determinados períodos. Por exemplo, na década de 1970, quando ocorre uma vigorosa rearticulação desse segmento, tendo seu ápice em 1978, com a criação do Movimento Negro Unificado (MNU). Também são marcos históricos importantes as ações empreendidas no ano de 1988, centenário da Abolição; no ano de 1995, quando se rememoraram os 300 anos da morte de Zumbi dos Palmares; e em 2001, na época da III Conferência Mundial contra o Racismo, Discriminação Racial, Xenofobia e Intolerâncias Correlatas, em Durban, na África do Sul.

As experiências educativas realizadas por organizações não governamentais (ONGs), bem como por outras formas de organização do movimento negro, em articulação com secretarias da educação ou de forma independente são ricas e múltiplas. Embora sejam ainda insuficientes os registros sobre elas, sabemos que existiram, existem e se consolidaram com o passar dos tempos. Tais mobilizações provocaram, em diferentes níveis governamentais, a criação de programas ou atividades de estímulo à diversidade étnico-racial nos programas de ensino.

Essas ações se consolidaram como parte integrante da educação brasileira a partir de 2003, quando ocorre a alteração dos artigos 26-A e 79-B da Lei de Diretrizes 
e Bases da Educação (LDB) (lei n. 10.639 de 2003 e lei n. 11.645 de 2008), explicitando de maneira contundente a obrigatoriedade dos sistemas educacionais brasileiros contemplarem em seus currículos questões relativas à história de negros e indígenas. É nesse espaço de constituição de um campo de conhecimento sistematizado sobre a formação de professores da educação infantil e as prescrições legais para o trabalho com a diversidade étnico-racial que esta pesquisa se insere. Particularmente, investigamos como professoras da educação infantil, após participarem de cursos, mobilizam esses saberes para a construção de um currículo nessa etapa educacional que contemple esta abordagem.

O interesse por essa etapa da educação básica se deve ao fato de que, apesar de ter extrema importância no desenvolvimento do ser humano, não tem sido, até o momento, o foco principal das pesquisas que tratam da diversidade étnico-racial e educação no Brasil. Somente no final da década de 1990 é que surgiram alguns trabalhos de pesquisa abarcando essa etapa, mas ainda são poucos e não deram conta de abranger todas as dimensões das muitas variáveis presentes nesse contexto.

Inicialmente, foram feitos esforços para conhecer as trajetórias de instituição desses cursos nas secretarias. Como são realizados? Quem os realiza? Por que os realizam? Para apreender tais caminhos, fizemos entrevistas semiestruturadas com gestores (com alguns, a entrevista foi por $e$-mail) responsáveis pelo desenvolvimento dos cursos em cada uma das secretarias. Também realizamos entrevistas semiestruturadas com dez profissionais (professoras e monitoras) da educação infantil. Foram coletados vários documentos sobre os cursos e sobre como a diversidade étnico-racial se institui como tema de formação nas ações das secretarias, especialmente para professores de educação infantil.

Definimos três grupos de perguntas, tanto para os gestores como para as professoras. Os grupos de questões dos gestores diziam respeito a aspectos como: a) implementação; b) execução; e c) continuidade. Para as professoras, foram: a) formação; b) curso; e c) sua prática pedagógica. $\mathrm{Na}$ interpretação das entrevistas, buscamos como regra a consideração das categorias arquitetadoras do discurso das professoras, tal como elas se evidenciaram nas respostas, associando-as ao quadro dos eixos apresentados para a condução destas. Não se tratava, simplesmente, de aplicar as ideias e conceitos dos autores que apoiavam esta pesquisa, mas de permitir que essas referências teóricas ajudassem a perceber, identificar e procurar explicar como e por que as respostas estruturavam-se de tal maneira. Esse processo era acompanhado de registros que procuravam estabelecer as categorias temáticas apresentadas pelos depoimentos. Na sequência, essas categorias foram analisadas, buscando-se compreender como foram estruturadas e os determinantes de sua escolha, compatibilizando-as com as entrevistas.

Bourdieu (2003, p. 713) afirma que a relação entre os sujeitos, na pesquisa, instaura-se na base de um acordo dos inconscientes. Ainda de acordo com esse autor, não é possível ignorar que nosso próprio ponto de vista tende a ser um ponto de vista sobre outro ponto de vista. Tal afirmação não introduz qualquer relativismo na interpretação, mas se esforça por assinalar as singularidades dos relatos dos sujeitos da pesquisa.

Para analisar como as professoras se apropriaram dos conteúdos dos cursos de formação frequentados por elas, fizemos uso da noção de apropriação, de acordo com Roger Chartier (1988). Sabemos que a questão desse autor era compreender, em primeira instância, as diferentes apropriações em relação à leitura de textos, mas consideramos ser possível estender o conceito de modo que pense e explicite peculiaridades da apropriação 
de conteúdos formadores em geral. A noção é aqui utilizada para dar conta das múltiplas possibilidades de combinação entre as propriedades socioculturais e psicológicas dos sujeitos e as especificidades dos objetos com os quais entram em contato.

Esse processo de apropriação ocorreu quando as professoras foram colocadas em contato com os conhecimentos do curso. Para se apropriarem deles, mobilizaram suas histórias pessoais com o tema da discriminação, às vezes situações nas quais elas mesmas tinham sido vítimas. Também recorreram a situações em que se viram envolvidas com o tema por diferentes motivos: porque estavam trabalhando numa comunidade de origem negra ou porque constataram que entre seus alunos havia discriminação. Enfim, as professoras recorreram aos seus capitais culturais ${ }^{1} \mathrm{e}$ saberes experienciais, apropriando-se dos conteúdos do curso para potencializá-los e transformá-los em práticas pedagógicas profundamente influenciadas pelos seus valores individuais, mobilizados pelas reflexões realizadas durante o curso de formação.

Os modos pelos quais se apropriam do que se trabalha nos cursos relacionam-se às curiosidades, ao momento histórico e às suas próprias necessidades, permitindo "[...] compreender a apropriação dos discursos, isto é, a maneira como estes afetam o leitor e o conduzem a uma nova norma de compreensão de si próprio e do mundo" (idem, p. 24).

Contudo, se é verdade que há especificidades nas apropriações de cada uma das professoras, também é pertinente falar de convergências, pois elas vivem sob o mesmo constructo ideológico. Isso confere às práticas analisadas semelhanças nos princípios e objetivos e, às vezes, nas estratégias, como é o caso da confecção de bonecas negras e da inclusão da literatura, valorizando o universo das culturas de origem afro-brasileira e africana. Considera-se que o estudo acerca das diferentes formas de apropriação é útil para compreender os movimentos pelos quais os saberes pedagógicos ou a formação docente são incorporados, nas diferentes situações, pelos professores de forma geral.

Essas convergências também resultam da longa mobilização realizada pelo movimento negro, que, de diferentes modos, tem influenciado a sociedade brasileira, procurando romper com a lógica da exclusão racial e social. A seguir, apresentaremos um pouco da história dos cursos analisados para depois apresentar alguns resultados do impacto destes nas práticas pedagógicas das professoras da primeira infância com as quais dialogamos.

\section{OS CURSOS}

Um dos cursos analisados ocorreu em Campo Grande/MS e fez parte de uma política instituída desde março de 2000 . O curso foi aplicado para aproximadamente 40 professores da educação infantil, em 2001, com 60 horas organizadas em cinco

1 O conceito liga-se às concepções de Bourdieu e refere-se ao conjunto de propriedades ou bens vinculados à formação e cultura que os sujeitos possuem associados à sua posição de classe, adquiridos no meio familiar ou escolar, por exemplo. Sobre a questão, ver Pierre Bourdieu, "Os três estados do capital cultural", tradução de Magali de Castro, em: Maria Alice Nogueira e Afrânio Catani (Orgs.), Os três escritos de educação, Petrópolis Vozes, 1998. 
módulos, sendo ministrado por uma equipe da Secretaria de Educação responsável pela política intitulada por eles de combate ao racismo.

Já o outro curso ocorreu em Campinas/SP, e para a sua realização a Secretaria de Educação contratou a ONG Centro de Estudos das Relações de Trabalho e Desigualdades (CEERT) (reconhecida por seu trabalho com o tema). Ele foi estruturado em três módulos e, diferentemente do curso em Campo Grande/MS, que foi dirigido exclusivamente para professoras da primeira infância, participaram professores dos vários níveis da educação básica.

O processo de instituição de políticas de ação afirmativa apresenta semelhanças, tanto em Campinas quanto em Campo Grande, tais como o trabalho anterior do movimento negro, a presença nas secretarias de pessoas com vínculos com o movimento para viabilizar as ações internamente, a necessidade de um constante convencimento dos secretários sobre a importância de a secretaria incluir o tema da diversidade étnico-racial.

Em relação às diferenças, o que mais se evidenciou foi o investimento. $\mathrm{Na}$ Secretaria de Educação de Campinas, o curso de formação foi parte de um projeto que incluiu a aquisição de material didático, a realização de outros cursos e oficinas para os professores e a composição de uma equipe para executar um programa formalmente instituído, exposições de trabalhos e ações culturais para os alunos da rede. Os investimentos não visavam apenas à etapa da educação infantil, mas o fato de as secretarias municipais serem responsáveis por ela colaborou para que essas ações chegassem também à primeira infância.

Em Campo Grande, o curso de formação realizado foi a única ação dirigida para a educação infantil. Depois dele, nenhuma aquisição de material ou outro tipo de investimento foram identificados nos documentos analisados. Outro diferencial percebido foi a instabilidade trabalhista dos gestores envolvidos. No momento em que encerramos a pesquisa, todos os gestores entrevistados já não estavam mais respondendo pelos seus setores.

Apesar dos modos diferenciados, nos quais a instituição das políticas ocorreu nas duas secretarias, ao analisarmos as entrevistas das professoras, tanto de uma cidade como de outra, foi possível organizar categorias que se apresentaram nos dois grupos. As categorias configuradas a partir do estudo das entrevistas foram: profissionalidade, ações formadoras, a dimensão político-administrativa, práticas pedagógicas, sendo esta última o foco de nossa abordagem neste artigo.

Nossa compreensão sobre práticas pedagógicas não se reduz somente à consideração da ação dos professores, mas leva em conta também o exame de suas relações com as diversas esferas do sistema de ensino e com o contexto social e cultural no qual a instituição educacional, os docentes e as crianças estão inseridos (Catani et.al., 2003). Ao discutirmos a prática pedagógica das professoras, analisamos os pressupostos pedagógicos, a dimensão curricular que o tema passa a ocupar em suas ações e também a dimensão metodológica. Verificamos ainda como os conteúdos apreendidos no curso foram transpostos de modo que se constituíssem em experiências de aprendizagem para as crianças da educação infantil (entre 2 e 5 anos), quais estratégias as professoras desenvolveram para sua efetivação no dia a dia e, por fim, buscamos compreender como as crianças reagem a um trabalho com esse enfoque. 


\section{OS PRINCÍPIOS PEDAGÓGICOS DE UM TRABALHO COM A ABORDAGEM DA DIVERSIDADE ÉTNICO-RACIAL NA PRIMEIRA INFÂNCIA}

Os pressupostos pedagógicos regem os modos que orientam o fazer e o pensar da educação, referem-se aos elementos essenciais e gerais numa proposta educacional, incluindo a reflexão metodológica acerca dos processos educativos e são pautados em princípios que expressam a concepção de educação e sociedade do profissional da educação. Nesse sentindo, ao investigarmos as práticas das professoras no que tange à diversidade, buscamos compreender quais os princípios que as nortearam para desenvolver suas ações. Apesar de se apresentarem difusos nos depoimentos, pode-se inferir alguns princípios que consideramos constituir uma contribuição importante para a construção de uma educação infantil que inclui a diversidade étnico-racial.

Organizamos, portanto, quatro princípios que orientaram as professoras entrevistadas no trabalho com a diversidade étnico-racial na educação infantile foram resultantes do processo de reflexão que os cursos de formação lhes proporcionaram. Ao apresentá-los, não os colocamos em ordem hierárquica, pois acreditamos que todos são importantes na construção de uma pedagogia para a diversidade étnico-racial na educação infantil.

O primeiro princípio identificado foi a necessária "coragem" para enfrentar o tema. Sem dúvida, trazer para a educação infantil os temas relativos à diversidade implica tomar uma atitude ousada e ética em relação à raça/cor e etnia. Incluir conhecimentos afro-brasileiros e indígenas e considerá-los tão importantes quanto os conhecimentos de origem europeia, que já são largamente trabalhados, é romper com uma tradição eurocêntrica de currículo, atitude nem sempre apoiada pelo conjunto de profissionais das instituições escolares.

Trabalhar com a diversidade étnico-racial, especialmente na educação infantil, exige, sim, que o professor assuma um compromisso ético e político. Apesar de haver nas propostas oficiais recomendações para que as instituições ofereçam esse tipo de conhecimento, sabemos que incluí-lo nas práticas pedagógicas é romper com a lógica da reprodução do racismo institucional, o que nos mostra que a professora, ao trazer a "coragem" como um princípio importante, sentiu-se desafiada e questionada na produção de sua prática.

Um exemplo desse processo vivenciado está no depoimento da professora Nafissatou, ${ }^{2}$ que, ao produzir com seus alunos um broche com a frase "Viva o dia 20 de novembro! Dia da consciência Negra!", ouviu de várias colegas que elas também fariam um, mas com outra frase "Viva o dia da consciência branca!", porque consideravam injusto "ter um dia para os negros e não ter dia para os brancos". Nafissatou relatou ainda que, além disso, ouviu várias piadas, e que algumas crianças que usaram o broche também foram importunadas pelas mesmas profissionais. Tal fato não é surpreendente,

2 As professoras serão identificadas por nomes de escritoras senegalesas contemporâneas; seus contos, poesias e romances destacam a resistência e a luta das mulheres africanas. Entendemos que as professoras entrevistadas também empreendem uma luta por justiça ao desenvolverem já na educação infantil práticas pedagógicas de combate ao racismo. Portanto, terão a palavra; Abibatou, Fama, Ken, Mariama, de Campo Grande/ MS; e Mame, Aminata, Nafissatou, Aissatou e Aicha, de Campinas/SP. 
pois sabemos que a persistência do racismo, do preconceito e da discriminação raciais são frutos de uma construção ideológica solidamente estruturada na sociedade brasileira.

Por isso, a coragem requerida pelas professoras entrevistadas de fato parece necessária, pois, mesmo com as legislações em vigor, sabemos que o tratamento pedagógico para a diversidade étnico-racial continua controverso e constitui-se num campo árido, no qual precisamos semear, regar, e cuidar cotidianamente para que as propostas possam produzir uma nova ação, "os bons frutos". Para atuar sobre esse tema, não bastam as leis, por isso os trabalhos iniciais exigem muita energia das professoras, que precisam pensar experiências de aprendizagem, metodologias, e ainda convencer colegas ou justificar sua ação aos gestores.

Um aspecto importante foi a unanimidade ao afirmarem a contribuição decisiva dos cursos para que elas pudessem organizar ações educativas que abordassem a diversidade étnico-racial sem medo de censuras ou de qualquer outro tipo de repreensão, como deboches das colegas, descrédito da direção ou outro fato qualquer que pudesse desestimulá-las a pôr em prática aquilo que aprenderam.

O segundo princípio é o da ludicidade. Ele se relaciona diretamente com o tipo de trabalho que devemos desenvolver com crianças pequenas. Tal princípio pode ser construído com base em algumas falas, como: "Para trabalhar com a criança, tem de ter bastante [elemento] concreto" ou "educação é mais lúdico mesmo". Tais argumentos expressam o que várias teorias que tratam da educação infantil indicam: é preciso considerar a ludicidade presente nessa fase para constituir qualquer tipo de trabalho. Piaget (1971) e Vigotski (1998), dois teóricos influentes nas discussões educacionais no Brasil, tratam da importância do jogo no processo de aprendizagem da criança, sejam eles simbólicos ou de regras. Também, o parecer que trata da revisão das Diretrizes Curriculares Nacionais para a Educação Infantil indica que

As propostas curriculares da Educação Infantil devem garantir que as crianças tenham experiências variadas com as diversas linguagens, reconhecendo que o mundo no qual estão inseridas, por força da própria cultura, é amplamente marcado por imagens, sons, falas e escritas. Nesse processo, é preciso valorizar o lúdico, as brincadeiras e as culturas infantis. (Brasil, 2012, p.14)

Também acreditamos que o lúdico é fundamental ao abordamos a diversidade étnico-racial na educação infantil; não se trata aqui de falar para os pequenos sobre os malefícios da escravidão no Brasil ou de como é feio discriminar, deve-se buscar no patrimônio cultural brasileiro referências que as levem a conhecer a história e a cultura afro-brasileira e indígena de modo que as valorizem. Trabalhar com esse patrimônio, com as suas diferentes linguagens, será de fato uma contribuição para se construir novos olhares sobre as histórias e as heranças culturais desses grupos ainda insuficientemente valorizadas no currículo da educação infantil

O terceiro princípio construído foi o de considerar as diferenças entre as pessoas como um valor positivo. Ele se apresentou em expressões do tipo: "A gente procura em várias ocasiões pautar a diferença como algo positivo", ou então: "A gente procura não hierarquizar a formação do simbólico na criança, por exemplo, da mesma forma que a gente conta história de príncipes e princesas loiras, a gente conta de princesas negras". 
Essas formulações expressam o princípio de que a ideia de diferença ${ }^{3}$ deve ser construída como algo positivo. Construir entre as crianças pequenas a concepção de que as diferenças observadas na convivência entre seus pares é algo positivo está na contramão da política de identidade que deseja estabelecer hierarquias entre as pessoas. Uma instituição de educação infantil, sempre que pautar seu trabalho por esse princípio, estará interrogando a si mesma e os outros espaços sociais sobre o tratamento dado a essa questão, possibilitando que as crianças pensem nas diferenças como uma experiência ao mesmo tempo particular e coletiva, que se estabelece na relação entre os sujeitos e não se constitui numa marca determinada de algum grupo específico.

Quando as professoras disseram que procuram "não hierarquizar a formação do simbólico na criança”, elas estão trazendo para suas práticas a ruptura do que Giroux (1995, p. 71) chama de disneyzação da cultura infantil. Para o autor, "não existe nada de inocente naquilo que as crianças aprendem sobre raça, tal como retratada no 'mundo mágico' da Disney" (idem, ibidem). Assim como não existe nada de inocente nas histórias infantis que apresentam, exclusivamente, um tipo físico como o portador da beleza, da bondade, da riqueza ou da magia. Por isso, cada vez que essas professoras possibilitam que as crianças ouçam e vejam histórias com outras representações, elas estão travando uma luta contra os discursos vigentes e dominantes sobre os modos como as crianças devem se reconhecer como sujeitos e reconhecer o outro, e assim rompendo com hierarquias nas quais é valorizado o branco europeu e desvalorizadas todas as outras formas de ser diferente desse tipo considerado como o não étnico, ou seja, o padrão.

Esse princípio articula-se a outro, de fundamental importância, expresso no depoimento da professora Aicha, quando explica a mudança de atitude de uma criança:

Agora ele se identifica como negro, mas ele teve de aprender isso, ele teve de construir isso. Eu acho que a gente tem de respeitar isso na criança, a criança tem de construir essa identidade, não a gente impor essa identidade. Eu falo, a gente faz um trabalho, falando da cultura, falando do preconceito, mas a gente não fala para a criança: “Olha, você é negra. Olha você é negro, viu?”. Não. Acho que isso a criança constrói. Fazendo um trabalho positivo que mostre para ela que ser negro não é negativo, pelo contrário, que a gente tem muita coisa legal, e a gente tem de trabalhar com essas coisas. A gente tem de mostrar para as pessoas. Então, isso que faz a criança se identificar como negro faz a criança ser negra, mas não adianta falar: "Você é negro, você é branco...” (Educadora Aicha, entrevista concedida em 11 set. 2006)

Aqui reside uma das chaves fundamentais para as professoras que trabalham com esse tema. De fato, se consideramos as crianças sujeitos ativos e reflexivos, não podemos obrigá-las a assumir uma identidade, seja ela qual for, ainda que acreditemos ser mais saudável que uma criança negra (aos nossos olhos) se aceite, tenha orgulho de si e dos seus antepassados; a identidade, inclusive a étnico-racial, é socialmente construída. Não

3 Diferenças compreendidas aqui como "as diferenças culturais entre os diversos grupos sociais definidos em termos de divisões sociais, tais como classe, raça, etnia, gênero, sexualidade e nacionalidade". Tal definição encontra-se entre as explicações do termo em Tomaz Tadeu Silva, Teoria cultural e educação: um vocabulário crítico. Belo Horizonte, Autêntica, 2000. 
cabe à professora definir para a criança sua identidade, seja em qual for o âmbito. O que lhe cabe é fornecer elementos positivos nos quais as crianças negras e não negras possam se apoiar na constituição de sua identidade.

Com isso chegamos ao último princípio pedagógico, a criança tem de ter elementos que colaborem na construção de sua identidade racial de modo positivo, já que essa identidade não pode ser imposta, ou seja, o pleno desenvolvimento da criança previsto na LDB articula-se com a construção de uma identidade positiva que não poderá ser de fato contemplada em sua integridade se as instituições de educação infantil ignorar a dimensão étnico-racial.

Em síntese, os quatro princípios pedagógicos aqui organizados, tendo como referência as práticas desenvolvidas pelas professoras ao aplicarem os conhecimentos adquiridos no processo de formação, foram:

1. O educador tem de ter coragem para trabalhar esse tema;

2. O lúdico é importante no contexto das práticas com a diversidade étnico-racial;

3. A ideia de diferença deve ser construída com a criança como algo positivo;

4. A criança tem de ter elementos que colaborem na construção de sua identidade racial de modo positivo, já que essa identidade não deve ser imposta a ela.

Tais pressupostos articulam-se com a escolha das experiências a serem desenvolvidas no trabalho da educação infantil. Porém, a definição das experiências de aprendizagem mais adequadas nessa etapa da educação continua sob disputa política e teórica. O que ensinar? Como ensinar? Por isso, influenciar na construção do currículo que será trabalhado na educação infantil é o objetivo principal dos cursos de formação de professores para o desenvolvimento de uma pedagogia da diversidade étnico-racial, e assim colocar em prática as Diretrizes Curriculares Nacionais para a Educação das Relaçôes Étnicos-Raciais e para o Ensino de História e Cultura Afro-Brasileira e Africana e também as Diretrizes Curriculares Nacionais para a Educação Infantil.

Os cursos de formação de professores para a educação infantil devem possibilitar que estes sejam capazes de desenvolver experiências de aprendizagem nas quais as crianças se apropriem dos conhecimentos culturais e científicos produzidos pelos vários grupos étnico-raciais, especialmente negros e indígenas. $\mathrm{E}$ isso por meio de experiências com filmes, danças, arte, música, teatro, entre outras linguagens que tragam os saberes científicos, as lutas e resistências desses povos.

Ao considerar princípios norteadores para a organização curricular da educação infantil como espaço importante de consolidação da pedagogia da diversidade étnico-racial, nos pautamos em práticas da realidade, resultantes de ações de formação de professoras, que a partir de suas vivências, experiências e subjetividades se reconheceram como sujeitos e transformaram seus fazeres, pois novos saberes foram acrescentados àqueles que já possuíam. Para Sacristán (1998, p. 121), “um conteúdo passa a ser valioso e legítimo quando goza do aval social dos que têm poder para determinar sua validade; por isso, a fonte do currículo é a cultura que emana de uma sociedade".

A professora, sabendo que pode escolher as práticas de aprendizagem a serem desenvolvidas e que estas revelam a perspectiva de sociedade que se quer, compreende a importância de sua atuação. É essa consciência que produz as mudanças almejadas. No caso analisado, as professoras produziram um arcabouço metodológico próprio da educação infantil, representado em três tipos. $O$ primeiro se refere a atividades ligadas ao 
desenvolvimento da linguagem. No trabalho com o desenvolvimento da linguagem, foram citadas três atividades que consideramos novas e ricas para ao trabalho com a diversidade étnico-racial: a utilização da linguagem engajada; a leitura de livros conhecidos por novos prismas; a produção de livros como material didático; e a realização de entrevistas.

Como segundo tipo, há as atividades relacionadas ao fazer artístico: dramatizações, confecção de cartazes com imagens de pessoas de diferentes origens étnico-raciais, sejam originadas de recortes de revistas, sejam desenhadas pelas próprias crianças. Ilustração de livros pelas próprias crianças, desenho de histórias com personagens negros e/ou sobre um personagem negro, a participação em atividades públicas e a confecção de bonecas negras.

E por fim, o terceiro grupo de atividades relaciona-se à corporeidade, nas quais preponderam atividades que destacam as características físicas por meio de conversas, desfiles, momentos de "pentear" os cabelos, apreciação de fotografias, diálogos, a utilização do espelho como recurso para a apreciação de suas características físicas, e numa outra esfera se encontram as atividades com música afro-brasileira para cantar e dançar.

\section{AS CRIANÇAS E SUAS REAÇÕES DIANTE DO TEMA}

Os saberes da criança sobre o sentido de ser negro ou branco na sociedade brasileira têm origem na família, na educação informal, no ambiente de vida, na experiência com os pares, nas músicas que ouve, nas revistas e propagandas que vê, nas piadas que escuta, nos gestos que identifica, enfim na sua convivência social em diferentes âmbitos e por diferentes meios de linguagem. Assim, a aprendizagem sobre ser negro e ser branco ocorre de diferentes formas para cada criança e começa bem antes da entrada da criança na escola. As crianças envolvidas nessas atividades, aqui anteriormente referidas, tinham entre 18 meses e 5 anos e, como atores sociais que são, antes de entrar na instituição de educação infantil, já tinham algum tipo de referência sobre o seu pertencimento étnico-racial e o dos outros.

Esse "saber" que as crianças apresentam sobre o outro frequentemente está relacionado ao corpo. É o toque e a proximidade física dos corpos negros que são evitados pelas crianças brancas. No depoimento da educadora Aminata, podemos identificar como isso ocorre. Há duas dimensões importantes para serem analisadas por esse aspecto: o medo e a rejeição. A primeira é o medo manifesto pela criança branca em relação aos sujeitos negros. Esses sentimentos não se apresentam somente em relação às crianças, $o$ educador negro também é alvo, indicando que há um "saber" sobre o negro adquirido pela criança branca anterior à sua presença na instituição.

Quais seriam os "saberes" construídos em sua experiência que as levam a apresentar tais atitudes?

Certamente, é a aprendizagem social negativa sobre o que representam pessoas negras. A ideia do negro como pessoa feia, suja ou que é ladra, perigosa, malandra, assustadora, entre outras, permeia a construção do imaginário de todos nós. Esse medo é criado por meio de mecanismos simbólicos apresentados em diferentes veículos que

4 Essa questão sobre como crianças brancas reagem ao educador negro é matéria para um próximo artigo. Julgamos tal questão importantíssima para a discussão da diversidade étnico-racial, mas ainda é muito pouco trabalhada em pesquisas. 
trabalham com imagens. A pessoa negra está muitas vezes representada e associada a fatores negativos. Nos filmes e histórias infantis, a referência à cor preta é tradicionalmente a portadora do mal. A linguagem simbólica que habita as experiências infantis remetem as crianças a relacionarem o negro como assustador, perigoso, mau, o que inclui a pessoa negra.

A percepção de que as crianças brancas manifestam sentimentos de rejeição em relação às pessoas negras, adultas ou crianças, não se resume no fato de que essa rejeição se concretiza no momento em que é necessário tocar. Elas utilizam o seu "saber" experencial para fazer escolhas, principalmente na hora das brincadeiras. Nesses momentos, a criança negra é preterida.

Ao tomarmos contato com essa realidade por demais cruel, custamos a acreditar que são práticas realizadas por crianças pequenas, com idade variando de 18 meses a 5 anos, e então somos impelidos a dizer que são essas professoras que estão vendo coisas onde não há. No entanto, os relatos foram feitos por professoras negras e brancas. Segundo elas, é possível perceber os conflitos de origem étnico-racial, entre as crianças, em vários momentos do fazer pedagógico.

Desde uma coisa explícita assim: "Eu não quero essa menina perto de mim", "Essa neguinha perto de mim". Até questões assim: vamos formar pares para a festa junina. "Ah, eu não quero dançar com ele!". "Por quê?”. A criança não diz especificamente por que não quer dançar... mas você tem... você tem de ter um jogo de cintura como professora para montar os pares de maneira que a criança negra seja bem aceita como um par. Às vezes, até pela idade da criança isso não é específico, não é explícito. "Não quero dançar com ele porque ele é negro". Mas acaba na formação... "Ah, escolha o seu par”. E por que, às vezes, aquela criança não é escolhida? Então, você tem de ter uma intervenção como educadora para não deixar que isso aconteça, então, eu acho que sentir esse momento é sentir preconceito, né? (Educadora Aissatou, entrevista concedida em 14 set. 2006)

Porém, a criança negra não apresenta apenas um comportamento passivo diante de manifestações racistas. Há outra dimensão pouco analisada nos trabalhos que tratam da diversidade étnico-racial e crianças: a resistência da criança negra diante das atitudes discriminatórias de seus colegas.

A forma mais comum de resistência é a reação de agredir praticada por crianças negras que são ofendidas. Muitas crianças negras reagem desse modo na escola. E nem sempre elas são compreendidas pela comunidade escolar, que a acusa de ser violenta, mas, no entanto, não tem o mesmo procedimento com a criança que praticou a discriminação. Outras se isolam, e ambas passam a ser acompanhadas de novas marcas de exclusão dentro do ambiente escolar, consideradas como "agressivas", "esquisitas" ou "pouco participativas", como nos aponta estudos realizados por Cavalleiro (2005). Entretanto, identificamos outro modo de resistência pelas crianças negras. Há crianças que, mesmo diante desse ambiente hostil, conseguem se autoafirmar como negras e colaboram para que outras crianças passem a considerar essa uma possibilidade legítima de ser e estar no grupo.

As atitudes de resistência das crianças negras e ao mesmo tempo a construção de uma nova percepção da criança branca sobre a população negra, por meio das situações 
de ensino-aprendizagem organizadas pelas professoras, constituíram-se como ricos processos em que o empoderamento foi intensamente vivido pelas professoras e também pelas crianças negras. À medida que o trabalho com a abordagem da diversidade étnico-racial foi se desenvolvendo, as crianças foram sentindo-se com direitos, conforme apontam os relatos. Elas queriam ser penteadas, tocadas, enfim, cuidadas, e conseguiram dizer isso ao seu modo para as professoras. Mame, uma das professoras, revela um momento único na qual presencia um pequeno tomar a palavra e indicar para a professora a tarefa que lhe faz jus ao título:

Teve uma cena muito legal. A monitora estava no banheiro penteando, arrumando o cabelo para [as crianças] irem ao refeitório. Uma monitora pegou as meninas e outra pegou os meninos e o $\mathrm{V}$. tinha o cabelo cortadinho baixinho. A monitora não penteou o cabelo dele. E ele ficou do lado dela só observando. Na hora em que ela terminou de pentear o cabelo de todos, ele falou assim para ela: "Você não vai pentear o meu cabelo?". Ela se surpreendeu, olhou para mim assustada. "Ah, Mame, eu não fiz de propósito". Eu falei: "Eu sei que você não fez de propósito". "É que o cabelo dele está tão curtinho, está tão... que para mim já estava penteado. Mas, vem V., eu vou pentear o seu cabelo". É essa coisa do toque. Você está penteando o cabelo. Você está dando atenção, está tocando a criança. É como eu falei, a atenção, muitas vezes, era focada na beleza branca. $\mathrm{O}$ negro não tinha esse momento de carinho, de ser tocado. Eu achei interessante ele cobrar. Porque, até então, eles não tinham essa iniciativa, de cobrar... Ela começou a ficar mais atenta. (Educadora Mame, entrevista concedida em 13 set. 2006)

São esses investimentos que criam novas atmosferas nos espaços da educação infantil, produzindo ambientes mais saudáveis. Foram muitos e variados os modos pelos quais as professoras interferiram na transformação das percepções acerca da diversidade étnico-racial. Tais modos alcançaram a elas próprias e as professoras que não participaram do curso para a promoção da igualdade racial, mas foram motivadas a repensar suas práticas. Dessas transformações participaram também as crianças, que se perceberam sujeitos de direito pela ação do novo saber técnico e experiencial e potencialmente fértil na promoção de mudanças institucionais.

\section{CONSIDERAÇÕES FINAIS}

Uma das principais conclusões da pesquisa está no dizer das professoras, que afirmam perceber a discriminação no seu cotidiano escolar, mas precisam de oportunidades institucionais nas quais possam discutir e estudar o tema. Pelos depoimentos, podemos concluir que a segurança declarada por elas após o curso ocorreu porque passaram a dominar alguns conceitos e conhecimentos, colaborando para formularem respostas às manifestações de racismo na escola. Ou seja, atuar sobre a formação dos professores, de acordo com os relatos, é fundamental para gerar respostas ao problema.

As professoras salientaram que se perceberam menos tolerantes com qualquer tipo de discriminação, e o aprendido no curso possibilitou-lhes ter argumentos para intervir em situações de conflito. É claro que essas atitudes não se aplicam a todas as 
professoras entrevistadas. Uma delas apresentou uma atitude menos interessada no trabalho, realizando-o apenas em momentos específicos do ano letivo, e também uma compreensão sobre as relações raciais no Brasil ambíguas; ao mesmo tempo em que considerava a sociedade racista, argumentava a ausência de sua manifestação na escola onde atuava. No entanto, a maioria das entrevistadas apresentou um discurso marcado pelo compromisso com o combate ao racismo como uma necessidade premente no seu ambiente de trabalho.

Cursos como os analisados têm um caráter de ampliação nos modos de atuar dos professores, causando impacto benéfico nas suas práticas em sala de aula e influenciando a dinâmica de ensino-aprendizagem em diferentes áreas do conhecimento. Foi isso que nos relataram as professoras, que criaram metodologias, organizaram de modo autônomo os currículos, influenciaram na reformulação dos projetos pedagógicos, dominaram a metodologia de projetos e exigiram a compra de materiais, demonstrando esse impacto positivo em sua prática pedagógica, potencializando atitudes criativas e formuladoras de políticas.

É com dificuldades que cursos com essa abordagem conseguem espaço na tão disputada agenda de formação dos professores, seja na inicial, seja na continuada. Mesmo com tom otimista, a pesquisa nos alerta que o tratamento das relações étnico-raciais na educação, especialmente na infantil, enfrenta inúmeros obstáculos, permeados pela concepção ainda presente na sociedade brasileira do "mito da democracia racial". ${ }^{5}$ Essa ideia gera uma descrença na existência do preconceito e do racismo na sociedade brasileira, e em consequência disso muitos professores questionam a pertinência dessa discussão na educação. Aliada a essa concepção, a percepção da criança como ser ingênuo e pueril também colabora para o reconhecimento por parte dos professores de que esta temática é importante de ser trabalhada na educação infantil.

Por isso, as metodologias desenvolvidas nas formações devem proporcionar que o professor proceda a uma análise crítica da própria prática, estimulando uma atitude reflexiva sobre os acontecimentos de seu cotidiano escolar e os alicerçando aos conhecimentos essenciais para intervir na realidade concreta da instituição, sendo para isso necessário que ele reconheça o racismo institucional e estrutural da sociedade brasileira, rompendo com a ideologia do mito, o que pesquisas têm constatado que não é tarefa fácil, porque pede a quebra de paradigmas fortemente constituídos na sociedade brasileira.

Outro aspecto crítico ao desenvolvimento dessas propostas é a falta de investimentos por parte dos gestores, a constante troca de responsáveis à frente dessas iniciativas no interior das secretarias e a descontinuidade de espaços institucionais para o prosseguimento das práticas iniciadas nesses processos de formação.

Porém, mesmo com tais dificuldades, a pesquisa indica que essa formação descontinuada estimulou para que as professoras criassem metodologias e reorganizassem os currículos no intuito de incluir a temática da diversidade nos seus fazeres, influenciando

5 De acordo com Florestan Fernandes (1965), a democracia racial - ou seja, a ideia de que no Brasil não há preconceito, nem discriminação de origem racial, não passava de mito - tem sido largamente utilizada para denunciar a situação desigual que a população negra ocupa na sociedade brasileira. 
na reformulação dos projetos pedagógicos. Outro aspecto importante resultante desses processos de formação foi que as professoras passaram a solicitar aos seus gestores a compra de materiais, como bonecas negras e livros com personagens negros, positivamente representados. Essas atitudes se constituíram em novas práticas no trato da diversidade étnico-racial, o que sem dúvida é um avanço na construção de uma educação infantil que promova a igualdade racial.

\section{REFERÊNCIAS}

Alencastro, Felipe Luiz. Brasil. Folha de São Paulo - Jornal on-line. São Paulo,31 dez.2000. Caderno Mais. Disponível em: <http://www1.folha.uol.com.br/fsp/mais/fs3112200004. $\mathrm{htm}>$. Acesso em: 5 ago. 2011.

Bourdieu, Pierre. A miséria do mundo. 3. ed. Petrópolis: Vozes, 2003.

Brasil. Congresso Nacional. Lei n. 10.639, de 9 de janeiro de 2003. Altera a lei n. 9.394, de 20 de dezembro de 1996, que estabelece as diretrizes e bases da educação nacional, para incluir no currículo oficial da rede de ensino a obrigatoriedade de temática "História e Cultuta Afro-Brasileira”, e dá outras providências. Diário Oficial da União, Brasília, DF, 10 jan. 2003.

. MEC/SECAD/SEPPIR. Diretrizes Curriculares Nacionais para a Educação das Relaçôes Étnico-Raciais e para o Ensino de História e Cultura Afro-Brasileira e Africana e referenciais para a Formação de Professores. Brasilia, DF: Ministério da Educação, 2005.

.Congresso Nacional. Lei n. 11.645, de 10 de março de 2008. Altera a lei n. 9.394, de 20 de dezembro de 1996, modificada pela lei n. 10.639, de 9 janeiro de 2003, que estabelece as diretrizes e bases da educação nacional, para incluir no currículo oficial da rede de ensino a obrigatoriedade de temática "História e Cultuta Afro-Brasileira e Indígena". Diário Oficial da União, Brasilia, DF, 11 mar. 2008.

. Resolução n. 5, de 17 de dezembro de 2009. Diretrizes Curriculares Nacionais para a Educação Infantil. Diário Oficial da República Federativa do Brasil,Ministério da Educação/ Conselho Nacional de Educação/ Câmara de Educação Básica, Brasília, DF, 19 dez. 2009, seção 1, p. 18.

. Parecer n. 20, de 11 de novembro de 2009. Diário Oficial República Federativa do Brasil, Ministério da Educação/Conselho Nacional de Educação/Câmara de Educação Básica, Brasilia, DF, 9 dez. 2012, seção 1, p.14.

Campinas (Município). Secretaria de Educação do Município de Campinas. Currículo em Construção - Rede Municipal de Educação Infantil de Campinas. Campinas, SP, [1998?].

CASTELls, Manuel. Opoder da identidade: a era da informação: economia, sociedade e cultura 3. ed., v. 2. São Paulo: Paz e Terra, 1996.

Catani, Afrânio; Nogueira, Maria Alice (Orgs.). Pierre Bourdieu: escritos de educação. Petrópolis: Vozes, 2001.

Catanı, Denice Barbara et al. Docência, memória e gênero: estudos sobre formação. São Paulo: Escrituras Editora, 2003.

Cavalleiro, Eliane. Discriminación y pluralismo cultural em la escuela, São Paulo, Brasil. In: Discriminación y pluralismo cultural en la escuela, casos de Brasil, Chile, Colombia, 
México y Perú. Santiago: Oficina Regional de Educación para América Latina y el Caribe (OREALC)/Organização das Nações Unidas para a Educação, a Ciência e a Cultura (UNESCO), 2005. p. 26-36.

. Las familias como espacio de aprendizaje en intersección con otros espacios. Eliane Cavalleiro, (GELEDES, Brazil) In: Seminário Virtual “Educación PARA la inclusión A LO LARGO DE LA VIDA". Proceso preparatorio para la CONFINTEA V + 6. Pavimentando el camino a Bangkok.GEO / ICAE, 2005. Disponível em: <http://www.icae.org.uy/spa/ sgeoseminario3.html\#racial>. Acesso em: 11 dez. 2006.

Chartier, Roger. A história cultural entre práticas e representaçôes. Rio de Janeiro: Difel, 1988. Dias, Lucimar Rosa. No fio do horizonte: educadoras da primeira infância e o combate ao racismo. 2007. Tese (Doutorado em Educação) - Faculdade de Educação da Universidade de São Paulo, São Paulo, 2007.

Fernandes, Florestan. A integração do negro na sociedade de classes. São Paulo, Cia. Editora Nacional, 1965.

Giroux, Henry. A disneyzação da cultura infantil. In: Silva, Tomaz Tadeu; Moreira, Antonio Flávio (Orgs.). Territórios constestados: o currículo e os novos mapas políticos e culturais. Petrópolis: Vozes, 1995.

Mato Grosso do Sul (Estado). Secretaria de Estado de Trabalho e Assistência Social/ Secretaria de Estado de Educação de Mato Grosso do Sul. Proposta pedagógica: educação em ação. Mato Grosso do Sul, 2002.

Piaget,Jean. A formação do símbolo na criança: imitação, jogo e sonho, imagem e representação. Tradução de Alvaro Cabral. Rio de Janeiro: Zahar, 1971.

SACristán, José Gimeno; Gomez, Ángel I. Pérez. Compreender e transformar o ensino. Porto Alegre: ArtMed, 1998.

Silva; Tomas Tadeu (Org.). Identidade e diferenças. Petrópolis: Vozes, 2000.

Therrien, Jacques. Saber de experiência, identidade e competência profissional: como os docentes produzem sua profissão. Contexto e Educação, Ijuí, UNIJUÍ, v. 1, n. 1, p. 7-36, 1996. Thompson, Paul. A voz do passado: história oral. Rio de Janeiro: Paz e Terra, 2002.

Vigotski, L. S. A formação social da mente. 6. ed. São Paulo: Martins Fontes, 1998.

\section{SOBRE A AUTORA}

Lucimar Rosa Dias é doutora em educação pela Universidade de São Paulo (USP). Professora da Universidade Federal de Mato Grosso do Sul (UFMS). E-mail:lucimar_dias@uol.com.br 


\section{LUCIMAR ROSA DIAS}

Formação de professores, educação infantil e diversidade étnico-racial: saberes e fazeres nesse processo

Este artigo apresenta parte de pesquisa de doutorado, que teve como principal objetivo compreender os modos pelos quais professoras da primeira infância se apropriaram de conhecimentos adquiridos em cursos de formação continuada que tinham por objetivo estimular a inclusão de práticas pedagógicas que tratassem da diversidade étnico-racial. Foram analisadas duas experiências, uma desenvolvida pela Secretaria de Estado de Educação do Mato Grosso do Sul, em Campo Grande, e outra pela Secretaria Municipal de Educação de Campinas/ SP. O trabalho se ancora em concepções da teoria crítica da educação, para a qual as práticas pedagógicas estão relacionadas com as práticas sociais, sendo também tarefa do professor a construção de estratégias educacionais que fomentem o respeito da diversidade étnico-racial.

Palavras-chave: formação de professores; educação infantil; diversidade étnico-racial.

Teacher education, early childhood education and ethnic-racial diversity: knowledge and practice during this process

This article is part of a $P h D$ thesis that examines the ways early childhood teachers make use of the knowledge acquired during continuing education courses designed to stimulate pedagogical practices that addressed ethnic and racial diversity. We analyzed two experiences conducted by Mato Grosso do Sul State Department of Education and Campinas City Department of Education. The work is based on the concepts from the 
critical theory of education, according to which pedagogical practices are related to social practices and it is the teacher's task to build educational strategies that promote the respect for ethnic and racial diversity.

Keywords: teacher education; early childhood education; ethnic and racial diversity.

\section{Formación del profesorado, educación infantil y diversidad étnico-racial: el conocimiento y la práctica en este proceso}

Este articulo presenta parte de una investigación de doctorado cuyo principal objetivo es comprender los modos por los cuales profesoras de educación preescolar incorporaron conocimientos adquiridos en cursos de formación continuada que tenian por objetivo estimular la inclusión de prácticas pedagógicas relativas a la diversidad étnico-racial. Se analizaron dos experiencias, una desarrollada por la Secretaría de Estado de Educación de Mato Grosso do Sul, en Campo Grande-MS, y otra, por la Secretaría Municipal de Educación de Campinas-SP. El trabajo se basa en las concepciones de la teoría crítica de la educación, según las cuales las prácticas pedagógicas están relacionadas con las prácticas sociales, y es deber del profesor la construcción de estrategias educativas que fomenten el respeto a la diversidad étnico-racial.

Palabras clave:formación de profesores; educación Infantil; diversidad étnico-racial. 